\title{
Mobile Charge Generation Dynamics in P3HT:PCBM Observed by Time-Resolved Terahertz Spectroscopy
}

\author{
Cooke, D. G.; Krebs, Frederik C; Jepsen, Peter Uhd
}

Published in:

2012 Conference on Lasers and Electro-Optics

Link to article, DOI:

10.1364/CLEO_SI.2012.CM1L.1

Publication date:

2012

Document Version

Publisher's PDF, also known as Version of record

Link back to DTU Orbit

Citation $(A P A)$ :

Cooke, D. G., Krebs, F. C., \& Jepsen, P. U. (2012). Mobile Charge Generation Dynamics in P3HT:PCBM Observed by Time-Resolved Terahertz Spectroscopy. In 2012 Conference on Lasers and Electro-Optics [CM1L.1] Optical Society of America. CLEO Technical Digest https://doi.org/10.1364/CLEO SI.2012.CM1L.1

\section{General rights}

Copyright and moral rights for the publications made accessible in the public portal are retained by the authors and/or other copyright owners and it is a condition of accessing publications that users recognise and abide by the legal requirements associated with these rights.

- Users may download and print one copy of any publication from the public portal for the purpose of private study or research.

- You may not further distribute the material or use it for any profit-making activity or commercial gain

- You may freely distribute the URL identifying the publication in the public portal 


\title{
Mobile Charge Generation Dynamics in P3HT:PCBM Observed by Time-Resolved Terahertz Spectroscopy
}

\author{
D. G. Cooke ${ }^{1 \dagger}$, F. C. Krebs ${ }^{2}$ and P. Uhd Jepsen ${ }^{3}$ \\ ${ }^{1}$ Dept. of Physics, McGill University, Montreal, Quebec, Canada H3A 2T8 \\ ${ }^{2}$ Risø National Laboratory for Sustainable Energy, Technical University of Denmark, DK-4000 \\ Roskilde, Denmark \\ ${ }^{3}$ Dept. of Photonics Engineering, Technical University of Denmark, DK-2800, Kgs. Lyngby, \\ Denmark \\ ${ }^{\dagger}$ cooke@physics.mcgill.ca
}

\begin{abstract}
Ultra-broadband time-resolved terahertz spectroscopy is used to examine the sub-ps conductivity dynamics of a conjugated polymer bulk heterojunction film P3HT:PCBM. We directly observe mobile charge generation dynamics on a sub-100 fs time scale.

(c) 2011 Optical Society of America

OCIS codes: (300.6495) Spectroscopy, terahertz; (300.6500) Spectroscopy, time-resolved; (160.5470) Polymers
\end{abstract}

\section{Introduction}

Charge carrier generation in conjugated polymer bulk heterojunctions plays a determining role in the operation of solution based optoelectronics such as low cost and flexible photovoltaic cells [1]. Despite years of research, the mechanism for mobile charge generation is still not well understood, particularly within the first few picoseconds following photon absorption [2] . Optical probes with sub-ps resolution are typically not sensitive to the mobility of charge carriers, and so often rely on indirect evidence of free carriers. Here we apply ultra-broadband $\mathrm{THz}$ spectroscopy to directly probe the creation of mobile carriers on a sub-100 fs time scale in a device-ready, roll-to-roll processed poly-3-hexylthiophene / phenyl C60-butyric acid methyl ester (P3HT / PCBM) film.

\section{Experiment}

Our experiment is based on two-color THz generation in an air plasma yielding ultra-broadband pulses shown in Fig. 1(a) with a bandwidth of more than $15 \mathrm{THz}$ (inset Fig. 1(a)) [5, 6]. Half of the $3.0 \mathrm{~W}$ output from the $1 \mathrm{kHz}$ Ti:sapphire regenerative amplifier is split into three beams: generation, detection and excitation beams. The generation line undergoes second harmonic generation (SHG) in a $100 \mu \mathrm{m}$ thick BBO crystal and the 800 and $400 \mathrm{~nm}$ beams pass through a zero order half waveplate for $800 \mathrm{~nm}$ (full wave at $400 \mathrm{~nm}$ ) and are then focused by an off-axis parabolic mirror to produce a plasma in the dry nitrogen atmosphere inside the setup purge box, emitting a broadband $\mathrm{THz}$ pulse. The $\mathrm{THz}$ pulse is collimated and transmitted through a high resistivity Si beamsplitter before it is focused at the sample at normal incidence. The reflected beam is collimated and directed by the beamsplitter, a mirror and an off-axis parabolic mirror to share a focus with the $800 \mathrm{~nm}$ gating beam between two planar electrodes and the THz pulse is detected by air-biased coherent detection [3]. The $400 \mathrm{~nm}$ excitation beam is derived by SHG of the fundamental in a 100 micron thick BBO crystal and is co-linear with the THz probe pulse at a fluence of $570 \mu \mathrm{J} / \mathrm{cm}^{2}$. THz waveforms are recorded after reflection without $\left(\mathrm{E}_{r e f}(\mathrm{t})\right)$ an excitation pulse simultaneously with the differential $\Delta \mathrm{E}\left(\mathrm{t}, \tau_{p}\right)=\mathrm{E}_{r e f}(\mathrm{t})-\mathrm{E}_{p u m p}\left(\mathrm{t}, \tau_{p}\right)$ at pump-probe delay time $\tau_{p}$ where $\mathrm{E}_{\text {pump }}\left(\mathrm{t}, \tau_{p}\right)$ is the transient recorded when the sample is pumped. Fourier transform and subsequent analysis treating the thin excited film as a uniform sheet conductor enables the extraction of the complex conductivity spectrum over the reference pulse bandwidth [7]. The sample is the technologically promising P3HT/PCBM bulk heterojunction on a PET plastic substrate coated with a thin layer of $\mathrm{ZnO}$ that acts as a transport layer in an actual device. Further details of the sample preparation are given elsewhere [4]. The samples are annealed at $140^{\circ} \mathrm{C}$ for approximately 10 minutes during processing.

\section{Results}

Figure 1 shows $\mathrm{E}_{r e f}(\mathrm{t})$ and $\Delta \mathrm{E}\left(\mathrm{t}, \tau_{p}\right)$ transients taken 120 fs following excitation of the film. $\Delta \mathrm{E}\left(\mathrm{t}, \tau_{p}\right)$ reaches a maximum amplitude at $120 \mathrm{fs}$, which is 3 times the temporal resolution of the experiment given by the $40 \mathrm{fs}$ pump pulse duration. As the $\mathrm{THz}$ modulation is sensitive to the photoinduced sheet conductance of the film, we therefore assign the buildup of $\Delta \mathrm{E}\left(\mathrm{t}, \tau_{p}\right)$ to the generation of mobile charge carriers in the P3HT:PCBM film. 

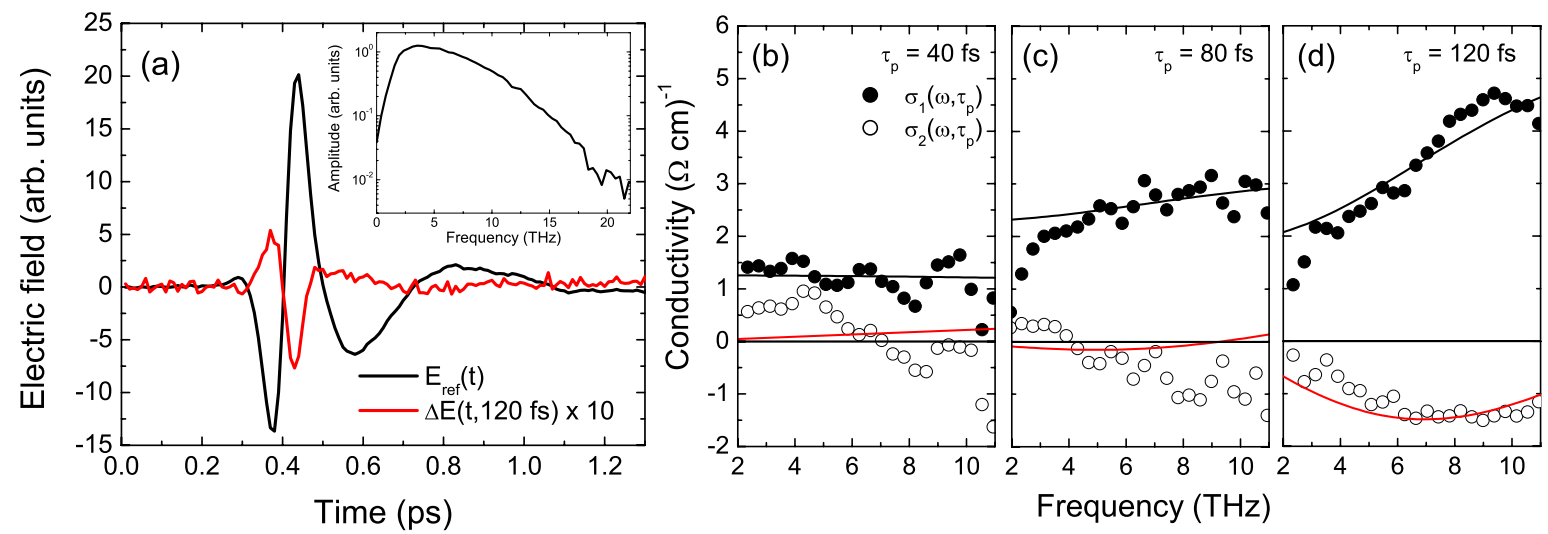

Fig. 1. (a) The time domain reference and differential THz transient at $\tau_{p}=120 \mathrm{fs}$ with reference pulse Fourier amplitude spectrum shown in the inset. The transient real (solid) and imaginary (hollow) components of the complex THz conductivity of the P3HT:PCBM film following $400 \mathrm{~nm}$ photoexcitation at a fluence of $570 \mu \mathrm{J} / \mathrm{cm}^{2}$ and $\tau_{p}=$ (b) $40 \mathrm{fs}$, (c) $80 \mathrm{fs}$ and (d) $120 \mathrm{fs}$.

The transient complex conductivity spectra, $\tilde{\sigma}(\omega)=\sigma_{1}\left(\omega, \tau_{p}\right)+i \sigma_{2}\left(\omega, \tau_{p}\right)$, for early $\tau_{p}$ are shown in Fig. 1(b-d) and can be best described by a phenomenological Drude-Smith model incorporating backscattering [8]. This model has the advantage of being able to continuously describe a material from a free carrier Drude response $(\mathrm{c}=0)$ to a highly disordered insulating response ( $\mathrm{c}=-1)$. For $\tau_{p}>80 \mathrm{fs}$, the main spectral features: 1) the increasing $\sigma_{1}(\omega)$ with frequency $\omega$ and negative imaginary conductivity $\sigma_{2}(\omega)$ have been observed previously at longer pump probe delays. However, for $\tau_{p}=40$ fs the response is best described by a free-carrier Drude response indicating that immediately following photoexcitation, there is a population of carriers that are highly delocalized along the polymer chain. The extracted scattering time $\tau$ remained constant at a value of approximately $7 \mathrm{fs}$ for all delay times. The plasma frequency $\omega_{p}=18.9 \mathrm{THz}$ at the $\tau_{p}=120 \mathrm{fs}$ peak, corresponding to a free carrier density of $7.5 \times 10^{18} \mathrm{~cm}^{-3}$ using an effective mass of $\mathrm{m}^{*}=1.7 \mathrm{~m}_{e}\left(\mathrm{~m}_{e}\right.$ is the electron mass). Comparing to the photon density, this corresponds to an initial mobile carrier yield of $20 \%$. Following the peak, the density is found to decay to $1 / 3$ its peak value exponentially with a time constant of $950 \mathrm{fs}$ (not shown). Considering other ultrafast studies finding exciton dissociation occurring on 4 - 9 ps time scales in annealed samples, we attribute this rapid decay to the formation of excitons or a bound charge transfer states from initially hot, delocalized population due to the excess photon energy of the $400 \mathrm{~nm}$ pump. Such an interpretation is in agreement with recent time-resolved photoluminescence measurements [9].

\section{Conclusions}

In conclusion, we have applied ultra-broadband reflective terahertz spectroscopy to observe the earliest photoconductivity dynamics ever observed in an organic semiconductor. We see evidence for delocalization of charges in band states on $40 \mathrm{fs}$ time scales, followed by a 1 ps decay into a bound, possibly an excitonic, state.

\section{Acknowledgements}

D. G. Cooke acknowledges financial support from the H. C. Ørsteds Foundation and NSERC.

\section{References}

1. G. Dennler, M. C. Scharber and C. J. Brabec, "Polymer-fullerene bulk-heterojunction solar cells," Adv. Mater. 21, 1323-1338 (2009).

2. T. M. Clarke and J. R. Durrant, "Charge photogeneration in organic solar cells," Chem. Rev. 110, 6736-6767 (2010).

3. J. Dai, X. Xie and X. -C. Zhang, "Detection of broadband terahertz waves with a laser-induced plasma in gases," Phys. Rev. Lett. 97, 103903 (2006).

4. J. Alstrup, M. Jørgensen, A. J. Medford and F. C. Krebs, "Ultra fast and parsimonious materials screening for polymer solar cells using differentially pumped slot-die coating," ACS Appl. Mater. Interfaces 2, 2819-2827 (2010).

5. D. J. Cook and R. M. Hochstrasser, "Intense terahertz pulses by four-wave rectification in air," Opt. Lett. 25, 1210-1212 (2000).

6. M. Kress, T. Löffler, S. Eden, M. Thomson and H. G. Roskos, "Terahertz-pulse generation by photoionization of air with laser pulses composed of both fundamental and second-harmonic waves," Opt. Lett. 29, 1120-1122 (2004).

7. P. Uhd Jepsen, D. G. Cooke and M. Koch, "Terahertz spectroscopy and imaging - Modern techniques and applications," Laser Photonics Rev. 5, 124-166 (2011).

8. N. V. Smith, "Classical generalization of the Drude formula for the optical conductivity," Phys. Rev. B 64, 155106 (2001).

9. N. Banerji, S. Cowan, E. Vauthey and A. J. Heeger, "Ultrafast relaxation of the poly(3-hexylthiophene) emission spectrum," J. Phys. Chem. C 115, 9726-9739 (2011). 